\title{
Environmental concerns about the effects of effluents from wastewater treatment plants in tourist areas of the Alps: toxicity in aquatic microorganisms
}

\author{
Valeria Di Nica ${ }^{1}$, Sara Villa ${ }^{1 \wedge}$, Valeria Lencioni ${ }^{2 *}$ \\ ${ }^{1}$ Department of Earth and Environmental Sciences, University of Milano-Bicocca, Piazza della Scienza 1, 20126 Milano, Italy; \\ ${ }^{2}$ Department of Invertebrate Zoology and Hydrobiology, MUSE-Museo delle Scienze, Corso del Lavoro e della Scienza 3 , 38122 \\ Trento, Italy \\ These authors have contributed equally to the present work.
}

\begin{abstract}
Are the effluents of wastewater treatment plants in high mountains of concern for aquatic biodiversity? To answer this question, we carried out an experimental study testing the short-term toxicity of some Pharmaceutical Active Compounds (PhACs) in the effluents of a plant in a mountain valley of the Italian Alps sampled during the high tourist season (i.e., the ski season) when PhACs contamination is higher. We used different tools, taking as a model the bacterium Aliivibrio fischeri: the "whole-mixture approach" (Microtox test), "component-based approach", predictive models "concentration addition (CA)", "independent action (IA)", and combination index (CI)". We investigated the nature of interactions potentially occurring among seven selected PhACs (clarithromycin, naproxen, acetaminophen (paracetamol), ibuprofen, diclofenac, carbamazepine, and amoxicillin). This study showed that anti-inflammatory ibuprofen and diclofenac have higher short-term toxicity $\left(\mathrm{IC}_{50}<100 \mathrm{mg} \mathrm{L}^{-1}\right)$ for A. fischeri compared with antibiotics, whose toxic effects are expected to become visible in the long term. Furthermore, based on the CI method, the seven PhACs seem not to interact in a synergistic or antagonistic way, but the final effect of their mixture seems to be equal to the sum of their individual effects. Notwithstanding the high tourist pressure, the Microtox test reported an overall toxicity of only $21 \%$, which drops to $7 \%$ in the receiving water body, the Vermigliana stream. These values, besides the predictions by CA and IA, are not alarming per se, i.e., the treated effluent of the plant in the period of maximum tourist pressure can be considered no harmful to aquatic microorganisms. However, based on other studies highlighting negative effects of the diluted treated effluent of the same plant on macroinvertebrate community structure, we suggest that other model organisms be considered, including algae, insects, and fish, to assess the real ecological risk to wildlife of an effluent. The experimental tests on $A$. fischeri are useful for fast, preliminary information on the level of risk for freshwater ecosystems, but they should be combined with field studies and experiments on the wild populations to increase the ecological realism.
\end{abstract}

\section{INTRODUCTION}

Effluents from wastewater treatment plants (WTPs) are recognised as a significant source of emerging contaminants in freshwaters (Daughton and Ternes, 1999; Carballa et al., 2005; Gosset et al., 2021). Among these, a fraction (30-90\%) of pharmaceutical active compounds ( $\mathrm{PhACs}$ ) in drugs is not metabolized and is excreted unchanged in the urine and faeces into the sewage (Monteiro and Boxall, 2010). Here, PhACs can persist and contaminate the WTP-

Corresponding author: valeria.lencioni@muse.it

Key words: Pharmaceuticals; mixture toxicity; concentration addition; combination index; mountain tourism; Alpine Convention.

Received: 11 June 2021.

Accepted: 12 August 2021.

This work is licensed under a Creative Commons Attribution NonCommercial 4.0 License (CC BY-NC 4.0).

${ }^{\circ}$ Copyright: the Author(s), 2021

Licensee PAGEPress, Italy

J. Limnol., 2021; 80(3):2044

DOI: 10.4081/jlimnol.2021.2044 receiving water bodies (Biel-Maeso et al. 2019; Gosset et $a l ., 2021)$. Due to their widespread use and continuous discharge, PhACs become pseudo-persistent contaminants in the aquatic environment (Daughton, 2005). Hundreds of different kinds of drug residues are found in water bodies worldwide at concentrations ranging from $\mathrm{ng} \mathrm{L}^{-1}$ to $\mu \mathrm{g} \mathrm{L}^{-1}$ (O'Flynn et al., 2021). Even environments notoriously considered uncontaminated, such as Alpine waters, can be affected by this type of pollution (Alpine Convention, 2009). Indeed, high PhACs concentrations can be measured in surface water of mountain localities downstream of WTPs (Villa et al., 2020), often in association with intense tourist activities, above all during the winter ski season (Mandaric et al., 2017; Villa et al., 2020). WTPs of high mountain localities are often designed to serve a small resident population. In some periods of the year, typically from Christmas to Easter and to a lesser extent in mid-summer, these localities are crowded by tourists and the treatment plants can become overloaded (Alpine Convention, 2009). In winter, this greater wastewater discharge is exacerbated by low dilution capacity of alpine rivers in the low-flow winter period (Chiogna et al., 2016). This period is also the most critical for the benthic fauna living in the receiving streams exposed to a mixture of hundreds of PhACs and other emerging contaminants as well as to the negative effects of nutrient inputs (Lencioni et al., 2020). 
To date, no information has been published on the toxic effects on microorganisms of the effluents of WTPs in a mountain valley with high tourist activity. Within this context, we used the Microtox ${ }^{\circledR}$ test in a series of laboratory tests to assess the whole-mixture toxicity of the treated effluent from the WTP of a famous ski resort at the Tonale Pass (Trentino, Eastern Italian Alps). This test is frequently used to perform a first screening of the treated effluent toxicity using Aliivibrio fischeri (formerly Vibrio fischeri; bacterium) as a bioindicator (Deprez et al., 2012; Weltens et al., 2012, 2014). This test is fast, easy to perform, highly reproducible, standardised and inexpensive (Parvez et al., 2006). Notwithstanding its easy application, it does not allow us to know the contribution of each contaminant simultaneously present in the effluent in a complex, undefined mixture (Groten et al., 2001), i.e. which contaminants drive the overall toxicity, or if overall toxicity depends on chemical-biological interactions among contaminants (Kortenkamp et al., 2009). To answer these questions, we used the "whole-mixture approach" followed by the "component-based approach" that links the results obtained from a specific mixture to single chemical components (van Gestel et al., 2011). This link allows generalising of results to different exposure scenarios, becoming the basis of the toxicity predictions (van Gestel et al., 2011). According to the componentbased approach, it is possible to estimate their overall toxicity, starting from information on the individual components of the environmental mixture (e.g., which chemical components are present, what is their mode of action, and what effects they exert as individual agents) (Kortenkamp et al., 2009).

We subsequently compared the toxicity of the experimental mixture with predictions obtained by applying two commonly used models, the concentration addition (CA) and the independent action (IA) (Loewe and Muischnek, 1926). Finally, we investigated the nature of interactions potentially occurring among selected $\mathrm{PhACs}$ by applying the combination index (CI) method. Both CA and IA are applied for mixtures of compounds having respectively the same mode of action (MoA) or different MoA against the selected endpoint (Loewe and Muischnek, 1926; Bliss, 1939). CA and IA estimate the toxicity of the mixture additively: additivity of concentrations (CA) and additivity of effects (IA). The idea behind the CA model is that if all the components of a mixture have the same or similar MoA, they behave towards the biological target as if they are the same chemical, so each could be replaced by another chemical at an equipotent concentration (e.g., at $\mathrm{EC}_{50}=50 \%$ Effective Concentration), without changing the final toxic effect of the mixture. The CA model implies that a significant mixture effect can be detected even if mixture constituents are present in concentrations that do not induce individual toxicity. This phenomenon is known as the principle of something from "nothing" (Silva et al., 2002; Thrupp et al., 2018). Conversely, in the case of the IA model, the concentrations of chemical components of a mixture cannot be added, as they are assumed to have different MoAs and they cannot be considered as homogeneous quantities. In this case, the overall effect of the mixture is estimated from the sum of the effects of the individual components (Bliss, 1939; Loewe and Muischnek, 1926). The important assumption behind the concepts of CA and IA models is the absence of chemical or biochemical interactions among substances in the mixture (i.e., the assumption of simple additivity) (Backhaus, 2014).

However, more realistically, interactions and/or biological interference among chemicals could occur at different levels in the environment (SCHER, SCCS, SCENIHR, 2012), leading to a higher or lower toxic effect than expected from CA or IA models, e.g., more than additive or synergistic effects and less than additive or antagonistic effects, respectively (Kienzler et al., 2014).

More recently, the CI method has been employed to study the joint effects of environmentally relevant mixtures of toxicants (Gonzalez-Pleiter et al., 2013; RodeaPalomares et al., 2010; Di Nica et al., 2016, 2017a, 2017b). This method was historically used in pharmacology to assess and quantify the nature of interactions among pharmaceuticals, revealing the occurrence of synergism or antagonism (Chou and Talalay, 1983). The CI concept has the great advantage of application without a priori knowledge of the MoA of chemicals (Chou, 2006).

Overall, this study, based on experimental and modelling data, gives new insights into the toxicity of treated effluents from WTPs and selected PhACs and their potential hazard for freshwater populations, which can be generalized to a larger territorial scale and to other mountain stream ecosystems.

\section{METHODS}

\section{Water sampling, selection of pharmaceuticals and mixture preparation}

The treated effluent was collected from the Tonale Pass WTP (1799 m asl; (http://adep.heidix.net/plant. html?PT), downstream of the Tonale Pass village, a famous ski resort in the Italian Alps $\left(46^{\circ} \mathrm{N}, 10^{\circ} \mathrm{E}, 1884 \mathrm{~m}\right.$ asl, Trentino Province). This WTP is equipped with conventional treatments (oxidation, secondary sedimentation) and represents a source of PhACs for the receiving stream (the Vermigliana stream), especially in winter due to the high number of tourists. This WTP was designed to serve 10,000 equivalent inhabitants but the population increases from 239 local inhabitants in 2021 (http://italia.indettaglio.it/ita/trentinoaltoadige/trento_vermiglio_passo- 
tonale.html) up to, every year as average, about 400,000 total and 190,000 respectively during the winter and the summer high tourist seasons (ISPAT - Annuario on-line, www.statweb.provincia.tn.it).

The sampling of the effluent was carried out on 6 March of 2017, the day after the end of the highest tourist pressure occurring during the Carnival holidays. Three samples were collected in sterile $1 \mathrm{~L}$ graduated polypropylene (PP) water bottles (from LP Italiana, Milan, Italy), kept refrigerated during the transport, and subsequently frozen at $-20^{\circ} \mathrm{C}$ within $2 \mathrm{~h}$ from sampling.

Before performing the acute toxicity tests, the $\mathrm{pH}$ of samples was measured and adjusted in the $\mathrm{pH}$ range between 6.0 and 8.5 following the DIN EN ISO 11348-3 procedures for the assessment of bioluminescence inhibition effects of aqueous samples on A. fischeri. In addition, to reproduce the minimum osmotic pressure necessary for the survival of the bacterium, the osmolarity of the sample was adjusted by adding $2 \% \mathrm{NaCl}$ (DIN EN ISO 11348-3).

We assessed the toxicity on A. fischeri of a relevant mixture of $\mathrm{PhACs}$ potentially discharged in the water body, starting from the list of PhACs detected by Villa et al. (2020) in the Vermigliana stream downstream of the selected WTP. Generally, the number of chemicals discharged into surface waters is extremely high, and it would not be reasonable to consider all of them in the toxicity assessment of the resulting environmental mixture (Backhaus and Karlsson, 2014). It has been empirically observed that in realistic mixtures only a limited number of substances are responsible for almost all the toxicity of the entire mixture (Price et al., 2012; Backhaus and Karlsson, 2014). For instance, Backhaus and Karlsson (2014) proposed the analysis of the Toxicity Units (TU) distribution of compounds in a complex mixture as a tool to classify the substances present in order of "ecotoxicological importance". The TU is defined as the ratio of the concentration of an active substance (as) measured in the environment (e.g., surface waters) (measured environmental concentration - MEC) and the toxicity $\left(\mathrm{IC}_{50}\right)$ shown against a defined biological endpoint (e.g. A. fischeri) (eq. 1)
$T U=\frac{M E C s w}{I C 50}$

Where MEC is the measured environmental concentration of the PhACs in surface water; the $\mathrm{IC}_{50}$ is the $50 \%$ inhibition concentration value measured on $A$. fischeri. According to Backhaus and Karlsson (2014), almost 90\% of the overall toxicity of a complex mixture is caused by about the first five compounds in order of TU; whereas the first 10 compounds are responsible for about $100 \%$ of the overall toxicity. To select the PhACs potentially responsible for the overall toxicity of the receiving environmental mixture, we compared the MEC values of PhACs found downstream the WTP (data from Villa et al., 2020, see Tab. 1) with the acute toxicity values (IC50) exerted as single chemicals against A. fischeri (data from the literature, see Tab. 1). Seven PhACs, were selected among those detected in the Vermigliana stream having the highest TU values (Tab. 1):

non-steroidal anti-inflammatory drug (NSAID, including three drugs: ibuprofen, diclofenac, naproxen), antibiotics (including clarithromycin, amoxicillin), one analgesic (acetaminophen) and one anticonvulsant (carbamazepine). According to Backhaus and Karlsson (2014) these PhACs could be responsible for the 90$100 \%$ of the overall toxicity for aquatic microorganisms.

To obtain the information (i.e., concentration-response relationship of single substances that compose the mixture) necessary for the application of the predictive models, some single PhACs (clarithromycin, naproxen and acetaminophen) were tested to define their toxicity curve parameters ( $\mathrm{IC}_{50}$ and slope) on A. fischeri. The $\mathrm{IC}_{50}$ value and the parameters of the concentrationresponse curves (slope) of ibuprofen, diclofenac, carbamazepine and amoxicillin curves were available from literature (Di Nica et al., 2017a). These data besides other information on the single PhACs (e.g., mode of action) were included in the predictive models of the mixture toxicity and to investigate how they interact with each other (i.e., in a synergic or antagonist way).

Tab. 1. Toxicity Unit values $\left(\mathrm{TU}=\mathrm{MEC} / \mathrm{IC}_{50}\right)$ for $A$. fischeri of the selected pharmaceuticals (PhACs) detected in the Vermigliana stream, downstream of the Tonale Pass WTP. PhACs are listed for decreasing values of TU.

\begin{tabular}{lccc} 
PhACs & MEC $\left(\mathrm{ng} \mathrm{L}^{-1}\right)$ & $\mathrm{IC}_{50}\left(\mathrm{mg} \mathrm{L}^{-1}\right)$ & TU \\
Ibuprofen & $619.0^{\mathrm{a}}$ & $18.3^{\mathrm{b}}$ & $3.38 \mathrm{E}-05$ \\
\hline Clarithromycin & $80.37^{\mathrm{a}}$ & $12.1^{\mathrm{c}}$ & $6.65 \mathrm{E}-06$ \\
\hline Naproxen & $91.25^{\mathrm{a}}$ & $17.9^{\mathrm{c}}$ & $5.09 \mathrm{E}-06$ \\
\hline Diclofenac & $41.90^{\mathrm{a}}$ & $15.9^{\mathrm{b}}$ & $2.63 \mathrm{E}-06$ \\
\hline Acetaminophen & $744.0^{\mathrm{a}}$ & $567.5^{\mathrm{d}}$ & $1.31 \mathrm{E}-06$ \\
\hline Carbamazepine & $5.14^{\mathrm{a}}$ & $94.0^{\mathrm{b}}$ & $5.47 \mathrm{E}-08$ \\
\hline Amoxicillin & $79.70^{\mathrm{a}}$ & $2845^{\mathrm{b}}$ & $2.80 \mathrm{E}-08$
\end{tabular}

MEC, measured environmental concentration ( $\left.\mathrm{ng} \mathrm{L}^{-1}\right)$; $\mathrm{IC}_{50}$, inhibition concentration of the bioluminescent of $A$. fischeri $\left(\mathrm{mg} \mathrm{L}^{-1}\right)$ from literature: ${ }^{\mathrm{V}}$ Villa et al. (2020), ${ }^{b} \mathrm{Di}$ Nica et al. (2017a); 'Ortiz de Garcia et al. (2014); ${ }^{\mathrm{d} K i m}$ et al. (2007). 
Tab. 2. Non-linear regression models selected for each treatment group.

\begin{tabular}{lcc} 
Treated group & \multicolumn{1}{c}{ Mathematical model } \\
$\begin{array}{l}\text { Treated effluent } \\
\text { MixMEC }\end{array}$ & Two parameters Weibull (W2.2) & $f=1-\operatorname{esp}(-\exp (\beta 2)-\ln \ln (c)-\ln \ln (\beta 1)))$ \\
$\begin{array}{l}\text { Clarithromycin } \\
\text { Acetaminophen }\end{array}$ & & $f=\varphi(\beta 2(\ln \ln (c)-\ln \ln (\beta 1)))$ \\
Naproxen & Two parameters Log Normal $(\mathrm{LN} .2)$ & (eq. 2) \\
\hline
\end{tabular}

\section{Stock solutions and testing procedure}

Clarithromycin, naproxen, and acetaminophen were from Sigma-Aldrich laboratories at the highest degree of purity. Clarithromycin and naproxen, having a low solubility in the saline water, were pre-dissolved in dimethyl sulfoxide (DMSO) and then in saline water. The concentration of DMSO in the tested solutions was less than $1 \%(\mathrm{v} / \mathrm{v})$, as requested by the OECD guidance document (2000) and according to Villa et al. (2018a, 2018b). The $\mathrm{pH}$ of the final solutions was adjusted in the range between 6.0 and 8.5 using a pH meter (model 250; Denver Instrument) by adding NaOH 0.1 M (DIN EN ISO 11348-3, 2007).

A stock solution of acetaminophen was prepared directly in the saline water solution $(2 \% \mathrm{NaCl})$ used for the tests, according to the method indicated by Vighi et al. (2009).

The multicomponent mixture (mixMEC) was prepared by combining the seven PhACs according to a fixed concentration ratio corresponding to the respective MECs value (MEC are from Villa et al., 2020). To describe the entire concentration-response curve, the total concentrations of the mixture were systematically varied using an appropriate dilution factor and keeping constant the concentration ratio among the single compounds in the mixture.

Tests were performed following the operating protocol and the conditions provided by the instruction manual of the Microtox ${ }^{\circledR}$ system (Acute toxicity test, Azur Environmental, 1998; "whole effluent toxicity") procedure for the effluent, and "basic test" procedure for single PhACs and their mixture). The Microtox ${ }^{\circledR}$ test is based on the measurement of the bioluminescence inhibition of the bacterium A. fischeri exposed to toxic agents or environmental samples. The inhibition of bioluminescence was measured in the acute mode using a Microtox ${ }^{\circledR}$ model 500 analyzer. The freeze-dried bacteria and the reconstitute solution were acquired from Ecotox LDS S.r.l. (Milan, Italy). Bacteria were exposed to the test samples (treated effluent, single chemicals and their mixture) for 5 and $15 \mathrm{~min}$ at the temperature of $15^{\circ} \mathrm{C}$. Only the inhibition data obtained after the 15-min of exposure were used for the final elaborations, due to the very negligible difference with results obtained after $5 \mathrm{~min}$. The inhibition of the bacterial bioluminescence concerning the control provides the toxic effect $\left(\mathrm{IC}_{\mathrm{x}}\right)$ of the samples.

Toxicity tests of each group tested (treated effluent, single chemicals and their mixture) were performed in a duplicate of one control and nine different dilutions obtained with serial dilutions in a $2 \% \mathrm{NaCl}$ solution (dilution factor used was of 1.5 and 2). The aliquots of the tested treated effluent ranged from $100 \%$ to $0.4 \%$ (Tab. S1). The aliquots of WTP output water were tested in six replicates. For each chemical and the mixture, tests were performed twice for a total of four replicates for each concentration. In single chemical tests and their mixture, the nominal concentration was considered.

\section{Statistical analyses}

The probability of the occurrence of a toxicity event $\mathrm{IC}_{\mathrm{x}}$ (bioluminescence inhibition), as a function of the chemical concentration $c$ (or fraction of the environmental sample), and a vector of parameters $(\beta 1 ; \beta 2)$ were obtained using non-linear regression models. The most appropriate model to fit the concentration-response relationship for each group of treatment (effluent, single chemicals and their mixture) was obtained by analysing the goodness of fit of the different mathematical models (i.e., Weibull; Log-Normal; Logistic and Log Logistic with two, three and four parameters) through the functions log likelihood and Akaike Information Criterion (AIC). The final mathematical models selected for each group of treatment are indicated in Tab. 2 (eq. 2 and eq. 3).

The statistical parameters of the estimated regression coefficients for both of the above-reported models were analysed to check their goodness of fit to the data obtained from each treatment group.

The analysis of the residues of the models was also carried out using the Kolmogorov-Smirnov test. All statistical analysis and the $\mathrm{IC}_{\mathrm{x}}$ values with $95 \%$ confidence intervals were obtained using the R software (R Core Team, 2021).

To reach a deep knowledge about the MoA of the tested chemicals on A. fischeri, the QSAR (Quantitative Structure Activity Relationship) equations developed by Vighi et al. (2009) for the prediction of the effect on $A$. fischeri of non-polar narcotic (eq. 4) and polar narcotics compounds (eq. 5) were applied:

$\log 1 / \mathrm{C}_{\text {narcotic }\left(\mathrm{mmol} \mathrm{L}^{-1}\right)}=0.94 \operatorname{logKow}-2.61$

$\left(n=23 ; R^{2}=0.92\right)$ 
$\log 1 / \mathrm{C}_{\text {polarnarcotic }\left(\mathrm{mmol} \mathrm{L}^{-1}\right)}=0.502 \operatorname{logKow}+0.294$ $\left(\mathrm{n}=23 ; \mathrm{R}^{2}=0.81\right)$

Both equations are based on the octanol-water partition coefficient (logKow) as a measure of the hydrophobicity of the molecules. Both models describe the so-called baseline toxicity of substances: i.e., the narcosis (expressed by Eq. 4) described as the toxic effect of a chemical having not a specific MoA towards an organism (inert chemical), and the polar-narcosis (expressed by eq. 5) described as the toxic effect of molecules that also have not a specific MoA but that exerts a slightly stronger toxic effect than non-polar narcosis (less inert chemicals) (Verhaar et al., 1992). In addition to these two primary processes, other two mechanisms of action causing the toxicity of a substance are identified: i.e., reactivity and specificity of the MoA (Verhaar et al., 1992). Reactive compounds are chemicals that exert a greater toxic effect than polar or nonpolar narcotics but they act non-selectively with chemical structures commonly found in biomolecules; whereas chemicals with a specific MoA specifically interact with a definite molecular receptor.

In this study, we applied both the QSAR models (in the case of ionisable PhACs, LogDow (distribution ration) is used instead of the LogKow). The LogDow values were chosen at the $\mathrm{pH}$ values close to that of the solution used for the Microtox tests. In Tab. S2 of the Supporting information, the LogDow values of the selected PhACs are reported together with other relevant physical-chemical parameters.

To estimate the effects on $A$. fischeri of the tested mixture $\left(\mathrm{IC}_{\mathrm{xmix}}\right)$, two predictive mathematical models were applied. For a multi-component mixture, the mathematical concept of CA can be expressed as follows (Berenbaum, 1985) (eq. 6):

$\sum_{i}^{n} \frac{C_{i}}{E C_{x i}}=1$

where $n$ is the number of chemicals in the mixture that cause the $x \%$ of the overall effect; $c_{i}$ is the concentration of the $i^{\text {th }}$ component in the mixture, and $\mathrm{EC}_{\mathrm{xi}}$ is the concentration of the $i^{\text {th }}$ component which provokes the same effect when considered individually.

The $c_{i} / E C_{x i}$ fraction is the Toxicity Unit (TU) of each chemical component (Sprague, 1970). The concentration of each component of the mixture is represented as an equi-effective fraction of the individual concentration, consequently, the behaviour of the mixture is additive if the sum of all the TUs is 1 .

Conversely, by applying the IA model, the overall effect of the mixture is predicted by summing the effects of the individual components, according to the statistical concept of independent random events. The toxic effect of each component is not influenced by the toxic effects of the other components of the mixture, as they act differently. Thus, the single toxic effects are added, and the probability that the components act simultaneously on the same target is subtracted. The IA mathematical concept can be expressed as follows:

$E\left(C_{m i x}\right)=1-\prod_{i=1}^{n}\left(1-E\left(C_{i}\right)\right.$

where $E\left(C_{\text {mix }}\right)$ is the effect estimated for the total concentration of the mixture; $C_{m i x}$ is the total concentration of the mixture, and $E\left(C_{i}\right)$ is the effect that the $i^{\text {th }}$ component would have if applied individually.

To investigate and quantify the nature of the interactions potentially occurring among the substances in the mixture, the CI method was applied (Chou, 1976, 2006; Chou and Talalay, 1984). For $n$ chemicals the equation CI can be expressed as follows (eq. 8):

$$
\begin{aligned}
& n(C I)_{x}=\sum_{j=1}^{n} \frac{(D)_{j}}{\left(D_{x}\right)_{j}}=\sum_{j=1}^{n} \frac{\left(D_{x}\right)_{1-n}\left\{\frac{[D]_{j}}{\sum_{1}^{n}[D]}\right\}}{\left(D_{m}\right)_{j}\left\{\frac{\left(f a_{x}\right)_{j}}{\left[1-\left(f a_{x}\right)_{j}\right]}\right\}^{1 / m_{j}}} C I= \\
& \frac{(D)_{1}}{\left(D_{x}\right)_{1}}+\frac{(D)_{2}}{\left(D_{x}\right)_{2}}=\frac{(D)_{1}}{\left(D_{m}\right)_{1}[f a /(1-f a)]^{1 / m_{1}}}+\frac{(D)_{2}}{\left(D_{m}\right)_{2}[f a /(1-f a)]^{1 / m_{2}}}
\end{aligned}
$$

where ${ }^{n}(C I)_{x}$ is the resulting $C I$ value for $n$ chemicals at $x \%$ of inhibition; $\left(D_{x}\right)_{1-n}$ is the sum of the concentrations of $n$ chemicals that exert in combination the $x \%$ of inhibition; $\left\{\left([D]_{j} / \Sigma[D]\right\}\right.$ is the proportionality of the concentration of each of the $n$ components which exerts in inhibition of $x \%$; $\left(D_{m}\right)_{j}\left\{\left(f_{a x}\right)_{j} /\left[1-\left(f_{a x}\right)_{j}\right]\right\}^{1 / m j}$ is the concentration of each component that alone exerts the $\mathrm{x} \%$; of inhibition, $D_{m}$ is the concentration of the median effect; $f_{a x}$ is the fractional inhibition at $\mathrm{x} \%$ inhibition; $m$ is the slope of the median concentration-effect curve.

From eq. 7, the presence of synergistic, additive and antagonistic effects can be calculated.

The CompuSyn program (Compusyn Inc., Paramus, NJ, USA) (Chou and Martin, 2005) was used to calculate the CI values for the mixMEC mixture at different ranges of effect levels. The $\mathrm{Fa}$ _CI graph was obtained (graph of $\mathrm{CI}$ values of the mixMEC mixture as a function of the different $F a$ ).

\section{RESULTS AND DISCUSSION}

\section{Toxic effect of treated effluent}

The bioluminescence inhibition values $\left(\mathrm{IC}_{\mathrm{x}}\right)$ achieved for $A$. fischeri at different dilutions of the treated effluent are indicated in Tab. 3, together with the statistical parameters describing the goodness of the mathematical model 
applied. Fig. 1 shows the concentration-response relationship obtained (relative bioluminescence inhibition as a function of the $\%$ of effluent).

The acute toxicity on A. fischeri of the effluent discharged from the Tonale Pass WTP before the dilution into the Vermigliana stream ( $100 \%$ of the treated effluent) achieved a mean value of $21 \%$. According to hydrological parameters calculated for the Vermigliana stream downstream from the WTP, the site-specific dilution factor in the water during the winter season was about 40 (Villa et al., 2020). This means that the realistic percentage of treated effluent in the stream in winter was about $2.5 \%$. The presence in the water of this percentage of treated effluent would lead to a bioluminescence inhibition of about 7\% $\left(\mathrm{IC}_{07}\right)(\mathrm{Tab} .3)$. These results revealed a modest toxicity of the effluent on aquatic microorganisms over the short term.

\section{Effects of individual chemicals on $A$. fischeri}

The $\mathrm{IC}_{10}$ and $\mathrm{IC}_{50}$ values obtained from the exposure of $A$. fischeri to the single PhACs are reported in Tab. 4,

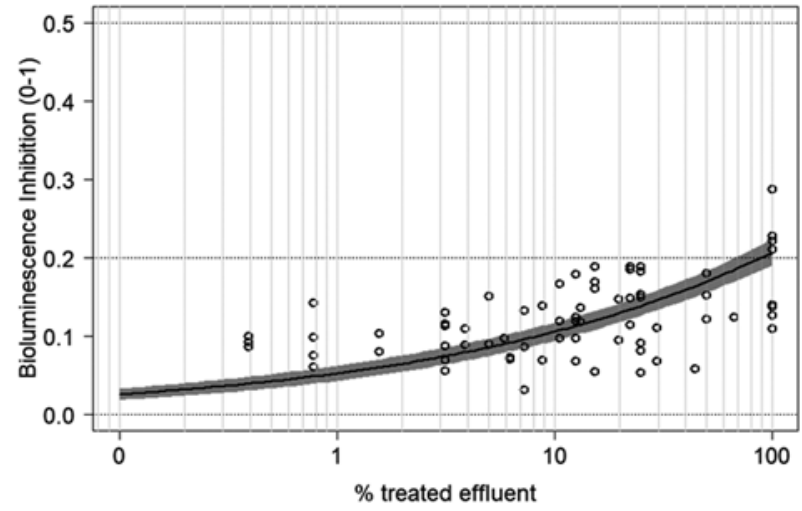

Fig. 1. Concentration-response curve for the treated effluent from the Tonale Pass wastewater treatment plant. The percentages of treated effluent in the tested sample are on the horizontal axis, and the relative values of bioluminescence inhibition (0-1) are on the vertical axis. The relative inhibition values of $0.5,0.2$ and 0.0 are indicated by horizontal lines.

Tab. 3. Bioluminescence inhibition values $\left(\mathrm{IC}_{\mathrm{x}}\right)$ of the treated effluent ( $\%$ of effluent in the tested sample), with $95 \%$ confidence intervals in brackets and statistical parameters of the selected regression model.

$\begin{array}{lcccccc}\mathrm{IC}_{\mathrm{x}} & \% \text { of treated effluent } & \text { Weibull model parameters } & \text { SE } & \text { t-value } & \text { p-value } & \text { n-1 } \\ \mathrm{IC}_{07} & 2.5 \%(1.3 \%-3.8 \%) & \beta 1 & 3.16 \mathrm{E}-01 & 2.06 \mathrm{E}-02 & 15.36 & <2.2 \mathrm{e}-16 \\ \mathrm{IC}_{10} & 8.3 \%(5.1 \%-11.5 \%) & \beta 2 & 1.03 \mathrm{E}+04 & 3.74 \mathrm{E}+03 & 2.7631 & 0.007333\end{array}$

SE, standard error.

Tab. 4. Acute toxicity values $\left(\mathrm{IC}_{10}\right.$ and $\left.\mathrm{IC}_{50}, \mathrm{mg} \mathrm{L}^{-1}\right)$ for $A$. fischeri for acetaminophen, clarithromycin, naproxen, the mixMEC, amoxicillin, carbamazepine, diclofenac, and ibuprofen [95\% mean confidence intervals in brackets]; the statistical parameters $\left(\beta_{1}, \beta_{2}\right)$ of the selected regression models are shown.

\begin{tabular}{|c|c|c|c|c|c|c|c|c|}
\hline & Mod. & $\mathrm{IC}_{10}$ & $\mathrm{IC}_{50}$ & Stat. par. & SE & t-value & p-value & $\mathrm{n}-1$ \\
\hline Diclofenac* & W1.4 & $\begin{array}{c}5.9 \\
{[5.03 ; 6.74]}\end{array}$ & $\begin{array}{c}15.9 \\
{[14.59 ; 17.26]}\end{array}$ & $\begin{array}{l}11.75 \\
-1.21\end{array}$ & $\begin{array}{l}0.4919 \\
0.0856\end{array}$ & $\begin{array}{c}23.89 \\
-14.082\end{array}$ & $\begin{array}{l}<0.001 \\
<0.001\end{array}$ & 50 \\
\hline Ibuprofen* & W2.2 & $\begin{array}{c}1.4 \\
{[0.99 ; 1.72]}\end{array}$ & $\begin{array}{c}18.3 \\
{[15.96 ; 20.58]}\end{array}$ & $\begin{array}{c}30.30 \\
0.72\end{array}$ & $\begin{array}{l}2.0776 \\
0.0346\end{array}$ & $\begin{array}{c}14.5865 \\
20.93\end{array}$ & $\begin{array}{l}<0.001 \\
<0.001\end{array}$ & 26 \\
\hline MixMEC & W2.2 & $\begin{array}{c}3.15 \\
{[2.10 ; 4.21]}\end{array}$ & $\begin{array}{c}66.9 \\
{[56.10 ; 77.70]}\end{array}$ & $\begin{array}{c}121.20 \\
0.62\end{array}$ & $\begin{array}{l}12.199 \\
0.0371\end{array}$ & $\begin{array}{l}9.9354 \\
16.629\end{array}$ & $\begin{array}{l}<0.001 \\
<0.001\end{array}$ & 40 \\
\hline Carbamazepine* & W2.2 & $\begin{array}{c}4.2 \\
{[2.85 ; 5.47]}\end{array}$ & $\begin{array}{c}94 \\
{[82.03 ; 105.91]}\end{array}$ & $\begin{array}{c}172.35 \\
0.60\end{array}$ & $\begin{array}{l}36.045 \\
0.0156\end{array}$ & $\begin{array}{l}3.753 \\
3.483 \\
\end{array}$ & $\begin{array}{l}<0.001 \\
<0.001\end{array}$ & 68 \\
\hline Naproxen & LN.2 & $\begin{array}{c}4.72 \\
{[3.99 ; 5.45]}\end{array}$ & $\begin{array}{c}131.06 \\
{[106.5 ; 155.6]}\end{array}$ & $\begin{array}{c}131.10 \\
0.39\end{array}$ & $\begin{array}{c}12.029 \\
0.016\end{array}$ & $\begin{array}{l}10.895 \\
24.123\end{array}$ & $\begin{array}{l}<0.001 \\
<0.001\end{array}$ & 31 \\
\hline Clarithromycin & W2.2 & $\begin{array}{c}28.65 \\
{[19.95 ; 37.35]}\end{array}$ & $\begin{array}{c}302.54 \\
{[171.10 ; 433.97]}\end{array}$ & $\begin{array}{c}478.50 \\
0.80\end{array}$ & $\begin{array}{c}122.42 \\
0.08703\end{array}$ & $\begin{array}{l}3.909 \\
9.184\end{array}$ & $\begin{array}{l}<0.001 \\
<0.001\end{array}$ & 33 \\
\hline Acetaminophen & LN.2 & $\begin{array}{c}74.13 \\
{[67.86 ; 80.40]}\end{array}$ & $\begin{array}{c}504.1 \\
{[483.6 ; 524.5]}\end{array}$ & $\begin{array}{c}504.10 \\
0.67\end{array}$ & $\begin{array}{c}9.743 \\
0.0142\end{array}$ & $\begin{array}{l}51.734 \\
47.217\end{array}$ & $\begin{array}{l}<0.001 \\
<0.001\end{array}$ & 18 \\
\hline Amoxicillin* & W2.2 & $\begin{array}{c}717.6 \\
{[537.5 ; 897.7]}\end{array}$ & $>1702$ & $\begin{array}{cc}\beta_{1} & 3719.40 \\
\beta_{2} & 1.37\end{array}$ & $\begin{array}{c}552.232 \\
0.1935\end{array}$ & $\begin{array}{l}6.7351 \\
7.0689 \\
\end{array}$ & $\begin{array}{l}<0.001 \\
<0.001\end{array}$ & 16 \\
\hline
\end{tabular}

SE, standard error; Mod., mathematical model; PhACs are listed for increasing values of $I C_{50} ;{ }^{*}$ data from Di Nica et al. (2017a). 
along with the statistical parameters of the selected regression models. In Fig. 2 the concentration-response curves of the single PhACs fitted by the selected regression models are shown. The three PhACs tested in this study (acetaminophen, clarithromycin, naproxen) showed an $\mathrm{IC}_{50}$ value greater than $100 \mathrm{mg} \mathrm{L}^{-1}$. The $50 \%$ inhibition concentration value was not reached for the antibiotic clarithromycin at the maximum concentration that it was possible to test; we estimated an $\mathrm{IC}_{50}$ value of $302.5 \mathrm{mg}$
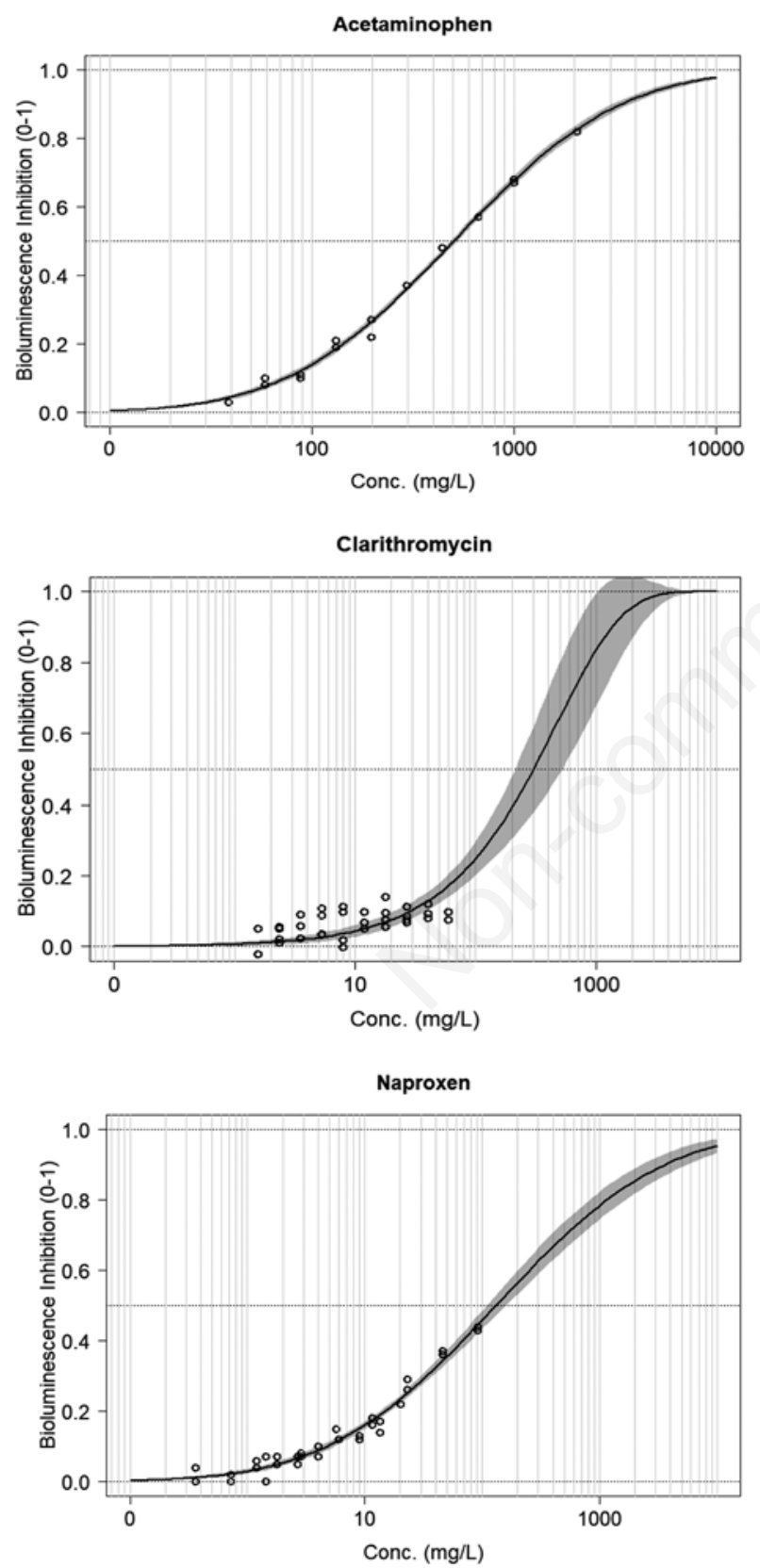

Fig. 2. Concentration-response curves for the pharmaceuticals: acetaminophen, clarithromycin, and naproxen.
$\mathrm{L}^{-1}$ from the application of the non-linear regression function. Similarly, the $\mathrm{IC}_{50}$ value found by Di Nica et al. (2017a) was not reached for the other antibiotic, amoxicillin. This is because antibiotics have a specific mechanism of action against $A$. fischeri, exerting their toxic effect mainly in the long term (e.g., after $24 \mathrm{~h}$ ) rather than the short term (e.g., $15 \mathrm{~min}$ ) (Backhaus and Grimme, 1999). This was expected because antibiotics such as clarithromycin that inhibit the biosynthesis of proteins show a delayed toxic effect over time (Backhaus and Grimme, 1999). On the contrary, the toxic effect exerted by compounds not having a specific mechanism of action (i.e., compounds having baseline toxicity that interfere in a predominant way with processes associated with membranes) is almost comparable over time (i.e., in the short and long terms) (Backhaus and Grimme, 1999).

According to the Globally Harmonized System of Classification and Labelling of Chemicals (GHS) (United Nations, 2013), based on the IC50 estimated in this study (for the NSAID naproxen, the antibiotic clarithromycin and the analgesic acetaminophen) or taken from the literature (for the NSAID diclofenac and ibuprofen, the antibiotic amoxicillin and the anticonvulsant carbamazepine), the anti-inflammatory ibuprofen and diclofenac were most toxic in the short term on A. fischeri, whereas the antibiotics were the least toxic.

In particular, based on GHS, diclofenac, ibuprofen, and carbamazepine are classified as harmful to aquatic microorganisms, having an IC50 between $10 \mathrm{mg} \mathrm{L}^{-1}$ and $100 \mathrm{mg} \mathrm{L}^{-1}$ a nd the other four PhACs as not acutely harmful, having an IC50 greater than $100 \mathrm{mg} \mathrm{L}^{-1}$.

\section{Experimental and predicted mixture toxicity}

The experimental values of $\mathrm{IC}_{10}\left(3.2 \mathrm{mg} \mathrm{L}^{-1}\right)$ and $\mathrm{IC}_{50}$ (66.9 $\mathrm{mg} \mathrm{L}^{-1}$ ) of the mixMEC mixture were between the highest and the lowest toxicity values of each of the components of the mixture (Tab. 4).

At the concentration corresponding to the sum of the MEC values in the Vermigliana stream $\left(1.66 \mathrm{E}^{-03} \mathrm{mg} \mathrm{L}^{-1}\right)$, no acute toxicity for A. fischeri was observed (Fig. 3). This result is consistent with those obtained by applying the whole mixture approach, whereby an acute bioluminescence inhibition below $10 \%$ was observed at the $\%$ of treated effluent realistically found in the Vermigliana stream (about 2.5\%).

The toxicity of the mixMEC mixture on A. fischeri was compared with the CA and IA model predictions (Fig. $3)$. The experimental toxicity of the tested mixture was well predicted by both models applied (CA and IA) in the lower part of the toxicity curve, while, with increasing toxicity, the prediction capability is lower. Both models seem to overestimate the real toxicity. The prediction window, i.e., the distance between the CA and IA curves, was very narrow. This occurs particularly when the mixture's 
chemicals have a comparable slope with an intermediate steepness of their concentration-response curves (Kortenkamp et al., 2009).

In our study, no synergistic or antagonistic interaction was detected among the seven components of the mixMEC mixture. In fact, the experimental toxic effect of all the $\mathrm{PhACs}$ in multicomponent combinations was predicted in additive terms (both concentrations and effects).

Synergistic or antagonistic responses seem to be confined to mixtures of few compounds ( 2 or 3 components) and are rarely observed in multicomponent mixtures, as in this case, where a sort of buffering effect seemed to occur (Backhaus, 2014). In addition, when the mixture is composed of chemicals without a specific MoA (narcotic compounds), as in our study, the overall toxic effect tends to be additive with the increase of the number of components (Warne and Hawker, 1995). By comparing the experimental toxicity data obtained for the single PhACs ( $\mathrm{IC}_{50}$ in Tab. 4) and the predictions obtained from the QSAR equations, we calculated the toxicity ratio values (see Tab. S3). It was not possible to apply the QSAR models for the antibiotic clarithromycin, as the experimental value of IC50 was not available. The results obtained are presented in Fig. 3. The experimental toxicity of acetaminophen and naproxen fell within the toxicity range of compounds of polar narcotic behaviour. This result is consistent with those previously obtained for all the other components of the mixture that exhibit also a polar narcotic behaviour against $A$. fischeri (Di Nica et al., 2017c).

The knowledge of the MoA of the substances is necessary for the application of predictive models of mixture toxicity. An environmental mixture can be composed of substances acting according to a similar MoA, according

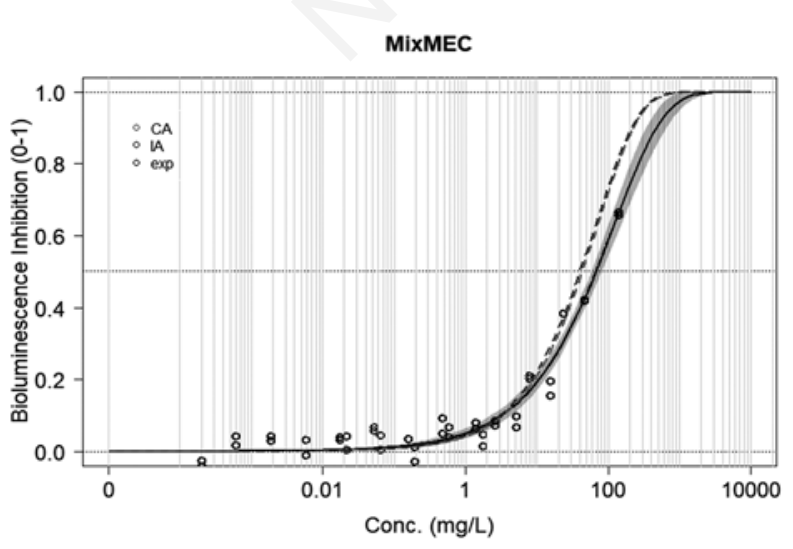

Fig. 3. Experimental (black points) and predicted (red and blue curves for the CA and IA models) concentration-response curves for the mixMEC mixture; mixMEC, ibuprofen acetaminophen, clarithromycin, naproxen, amoxicillin, carbamazepine, and diclofenac. to different MoA, or more likely by a combination of both. In our study, all the selected compounds apart from the antibiotic clarithromycin had a polar narcotic-like behaviour towards the test organism, and this can be assimilated to a common MoA. Therefore, the toxicity of the mixMEC mixture should be well predicted by applying the concept of additivity of concentration.

\section{The CI method}

The prediction values were obtained by applying the $\mathrm{CI}$ method at various effect levels up to the maximum concentration that was possible to test (corresponding to $65 \%$ of the effect level). The results (Fa) are reported in Tab. S4 and, for almost all the investigated effect levels, the CIs are between 0.5 and 2 . These results highlight the absence of interactions among the $\mathrm{PhACs}$ tested in multicomponent combinations. However, for effect levels above 55\% ( $\mathrm{Fa}$ $>0.55$ ), the CI values were higher than the threshold of 2 , indicating the existence of a slight antagonistic effect among the mixture components. A threshold of twice the deviation from the unit is generally applied to indicate the agreement between the experimental mixture toxicity and prediction obtained through the concentration additivity principle (i.e., CI values between 0.5 and 2) to indicate the absence of synergistic or antagonistic interactions (Belden et al., 2007; Cedergreen, 2014).

The application of the CI model confirmed the results obtained by means of the CA and IA predictions, i.e., the seven PhACs combined in a mixture have an additive type of response on A. fischeri at the high level of contamination (e.g., at a concentration of about $40 \mathrm{mg} \mathrm{L}^{-1}$ of $\mathrm{PhACs}$ in mixture).

As the tested concentration increases, the PhACs start to interact, producing lower toxicity than that predicted by the additive model (additivity of concentration). From the point of view of environmental risk management, the overestimation obtained with the predictive models does not pose a particular concern, as the prediction provided by the additivity concepts was sufficiently protective.

\section{CONCLUSIONS}

Our results show that the concentration of PhACs in the treated effluent from the Tonale Pass WTP, in the period of winter tourism peak, do not reach levels that can be harmful to aquatic microorganisms. Microtox results suggest that individual PhACs do not represent a hazard for the local biodiversity. Consistently, Lencioni et al. (2020) evaluated the ecological state and water quality of the Vermigliana stream, using the STAR_ICMi (Buffagni and Erba, 2008) and IBE (IRSA-CNR and APAT, 2003) indices, which use macroinvertebrates as biological indicators, and they found a good ecological 
state downstream from the Tonale Pass WTP, even during the winter season. However, some negative effects were found downstream of the WTP on alpha diversity of the macroinvertebrate community and at organism (e.g., mortality) and sub-organism levels (e.g., DNA damage) in local insect populations (Lencioni et al., 2020). Furthermore, Villa et al. (2020) assessed an ecological risk downstream of this treatment plant, comparing PhAC concentrations in the Vermigliana stream and the toxicological endpoints for aquatic organisms (algae, Daphnia, and fish). So, an ecological risk for the receiving water body cannot be totally excluded, especially for anti-inflammatory compounds, and possibly resulting from the input of nutrients and other organic and civil pollutants (e.g., soaps and oils).

Experimental tests on model species, such as A. fischeri, can be useful for preliminary and fast information on the level of risk for freshwater habitats and organisms in a screening phase. However, they should be combined with field studies and experiments on the local population to increase the ecological realism, including the use of other model organisms such as algae, insects, and fish.

Finally, these eco-toxicity data can be potentially used in ecological risk assessment of effluents of this and other WTPs in mountain tourist valleys, where during some periods of the year the receiving water bodies are contaminated by hundreds to thousands of PhACs. Given the importance of alpine waters as drinking water supplies for many Europeans, such studies are also recommended by the Water Framework Directive (European Commission, 2000). The direct toxicity assessment of WTP discharges represents an important tool to maintain or achieve ecological quality objectives in freshwaters.

\section{ACKNOWLEDGEMENTS}

This work was supported by the Cassa di Risparmio di Trento e Rovereto Foundation (CARITRO) within the RACE-TN project ('Valutazione del rischio ambientale dei contaminanti emergenti nei fiumi trentini: effetti sulla vita selvatica e sull'uomo'/'Environmental Risk assessment of emerging contaminants in Trentino rivers: effects on wildlife and human health', Grant n. 2015.0199; 2015-2018), by the MUSE-Science Museum of Trento and by the University of Milano-Bicocca. We thank two anonymous reviewers for their useful comments that improved the manuscript, and Peter Adler (Clemson University, Clemson, USA) and Patrick Ashe (Dublin) for English revision.

\section{CONFLICT OF INTEREST}

The authors declare no competing or financial interests.

\section{CONTRIBUTIONS}

VDN, investigation, formal analysis, data curation, visualization, original draft preparation; SV, conceptualization, supervision, methodology, investigation, review and editing; VL, conceptualization, supervision, project administration, funding acquisition, review and editing.

\section{REFERENCES}

Alpine Convention, 2009. Water and water management issues: Report on the state of the Alps. Alpine signals. Special edition p. 2. Innsbruck, Austria: Permanent Secretariat of the Alpine Convention.

Azur Environmental, 1998. Microtox System Operating manual. Azur Environmental, Carlsbad.

Backhaus T, Grimme LH, 1999. The toxicity of antibiotic agents to the luminescent bacterium Vibrio fischeri. Chemosphere 38:3291-3301.

Backhaus T, 2014. Medicines, shaken and stirred: a critical review on the ecotoxicology of pharmaceutical mixtures. Phil. Trans. R. Soc. B 369:20130585.

Backhaus T, Karlsson M, 2014. Screening level mixture risk assessment of pharmaceuticals in STP effluents. Water Res. 49:157-165.

Berenbaum MC, 1985. The expected effect of a combination of agents: the general solution. J. Theor. 114:413-31.

Belden JB, Gilliom RJ, Lydy MJ, 2007. How well can we predict the toxicity of pesticide mixtures to aquatic life? Integr. Environ. Assess. Manag. 3:364e372.

Biel-Maeso M, Corada-Fernández C, Lara-Martín PA, 2019. Removal of personal care products (PCPs) in wastewater and sludge treatment and their occurrence in receiving soils. Water Res. 150:129-139.

Bliss CI, 1939. The toxicity of poisons applied jointly. Ann. Appl. Biol. 26:585-615.

Buffagni A, Erba S, 2008. [Definizione dello stato ecologico dei fiumi sulla base dei macroinvertebrati bentonici per la 2000/60/CE(WFD): il sistema di classificazione MacrOper].[in Italian]. IRSA-CNR, Notiziario dei Metodi Analitici: 24-46.

Carballa M, Omil F, Lema JM, 2005. Removal of cosmetic ingredients and pharmaceuticals in sewage primary treatment. Water Res. 39:4790-4796.

Cedergreen N, 2014. Quantifying synergy: a systematic review of mixture toxicity studies within environmental toxicology. PLoS One 9:e96580.

Chiogna G, Majone B, Cano Paoli K, Diamantini E, Mallucci S, Stella E, Lencioni V, Zandonai F, Bellin A, 2016. A review of hydrological and chemical stressors in the Adige catchment and its ecological status. Sci. Total Environ. 540:429-443.

Chou TC, 1976. Derivation and properties of Michaelis-Menten type and Hill type equations for reference ligands. J. Theor. Biol. 59:253-254.

Chou TC, 2006. Theoretical basis, experimental design, and computerized simulation of synergism and antagonism in drug combination studies. Pharmacol. Rev. 58:621-681.

Chou TC, Martin N, 2005. CompuSyn for Drug Combinations: 
PC Software and User's Guide: A Computer Program for Quantitation of Synergism and Antagonism in Drug Combinations, and the Determination of IC50 and ED50 and LD50 Values. ComboSyn Inc, Paramus.

Chou TC, Talalay P, 1983. Analysis of combined drug effects: a new look at a very old problem. Trends Pharmacol. Sci. 4:450-454.

Chou TC, Talalay P, 1984. Quantitative analysis of dose-effect relationships: the combined effects of multiple drugs or enzyme inhibitors. Adv. Enzym. Regul. 22:27-55.

Connon RE, Geist J, Werner I, 2012. Effect-based tools for monitoring and predicting the ecotoxicological effects of chemicals in the aquatic environment. Sensors (Basel) 12:12741-12771.

Daughton CG, Ternes TA, 1999. Pharmaceuticals and personal care products in the environment: agents of subtle change? Environ. Health Perspect. 107:s907-938.

Daughton CG, 2005. "Emerging" chemicals as pollutants in the environment: A 21 st century perspective. Renew. Resour. J. 23:6-23.

Deprez K, Robbens J, Nobels I, Vanparys C, Vanermen G, Tirez K, Michiels L, Weltens R, 2012. DISCRISET: A battery of tests for fast waste classification - Application of tests on waste extracts. Waste Manage. 32: 2218-2228.

Di Nica V, Gallet J, Villa S, Mezzanotte V, 2017a. Toxicity of quaternary ammonium compounds (QACs) as single compounds and mixtures to aquatic non-target microorganisms: experimental data and predictive models. Ecotoxicol. Environ. Saf. 142:567-577.

Di Nica V, Villa S, Finizio A, 2016. Experimental and predicted toxicity of binary combinations of diclofenac sodium, carbamazepine and caffeine to Aliivibrio fischeri. Environ. Eng. Manag. J. 15(9):1971-1980.

Di Nica V, Villa S, Finizio A, 2017b. Toxicity of individual pharmaceuticals and their mixtures to Alivibrio fischeri: evidence of toxicological interactions in binary combinations. Environ. Toxicol. Chem. 36:815-822.

Di Nica V, Villa S, Finizio A, 2017c. Toxicity of individual pharmaceuticals and their mixtures to Aliivibrio fischeri: experimental results for single compounds and considerations of their mechanisms of action and potential acute effects on aquatic organisms. Environ. Toxicol. Chem. 36:807-814.

DIN EN ISO 11348-2, 2007. Water quality - Determination of the inhibitory effect of water samples on the light emission of Vibrio fischeri (Luminescent bacteria test) Method using liquid-dried bacteria.

Dong Y, Wang J, Ding L, Liu Y, 2013. Influence of cosolvents on low water-solubility chemicals to Photobacterium phosphoreum in acute toxicity test. Procedia Environ. Sci. 18:143-148.

Escher BI, Baumer A, Bittermann K, Henneberger L, Konig M, Kuhnert C, Kluver N, 2017. General baseline toxicity QSAR for nonpolar, polar and ionisable chemicals and their mixtures in the bioluminescence inhibition assay with Aliivibrio fischeri. Environ. Sci. 19:414-428.

European Commission, 2000. Directive 2000/60/EC. Establishing a framework for community action in the field of water policy. European Commission PE-Cons 3639/1/100 Rev 1.

González-Pleiter M, Gonzalo S, Rodea-Palomares I, Leganés F, Rosal R, Boltes K, Marco E, Fernández-Piñas F, 2013. Toxicity of five antibiotics and their mixtures towards photo- synthetic aquatic organisms: implications for environmental risk assessment. Water Res. 47:2050-64.

Gosset A, Wiest L, Fildier A, Libert C, Giroud B, Hammada M, Hervé M, Sibeud E, Vulliet E, Polomé P, Perrodin Y, 2021. Ecotoxicological risk assessment of contaminants of emerging concern identified by "suspect screening" from urban wastewater treatment plant effluents at a territorial scale. Sci. Total Environ. 778:146275.

Gosset A, Polomé P, Perrodin Y, 2020. Ecotoxicological risk assessment of micropollutants from treated urban wastewater effluents for watercourses at a territorial scale: Application and comparison of two approaches. Int. J. Hyg. Envir. Heal. 224:113437.

Groten JP, Feron VJ, Suhnel J, 2001. Toxicology of simple and complex mixtures. Trends Pharm. Sci. 22:316-322.

IRSA-CNR, APAT, 2003. [Metodi analitici per le acque. Manuali e Linee guida].[in Italian]. IRSA-CNR, APAT.

Kim Y, Choi K, Jung J, Park S, Kim P-G, Park J, 2007. Aquatic toxicity of acetaminophen, carbamazepine, cimetidine, diltiazem and six major sulfonamides, and their potential ecological risks in Korea. Environ. Int. 33:370-375.

Kienzler A, Berggren E, Bessems J, Bopp S, van der Linden S, Worth A, 2014. Assessment of mixtures - review of regulatory requirements and guidance. JRC Science for Policy Report, EUR 26675EN. Luxembourg: Publications Office of the European Union.

Kortenkamp A, Backhaus T, Faust M, 2009. State of the art report on mixture toxicity. Final report to the European Commission. Contract no. 070307/2007/485103/ETU/D.1.

Lencioni V, Bellamoli F, Paoli F, 2020. Multi-level effects of emerging contaminants on macroinvertebrates in Alpine streams: from DNA to the ecosystem. Ecol. Indic. 117:106660.

Loewe S, Muischne KH, 1926. Effect of combinations: Mathematical basis of problem. N-S Arch. Exp. Pathol. Physiol. 114:313-326.

Mandaric L, Diamantini E, Stella E, Cano-Paoli K, Valle-Sistac J, Molins-Delgado D, Bellin A, Chiogna G, Majone B, DiazCruz MS, Sabater S, Barcelo D, Petrovic M, 2017. Contamination sources and distribution patterns of pharmaceuticals and personal care products in Alpine rivers strongly affected by tourism. Sci. Total Environ. 590-591:484-494.

Monteiro SC, Boxall ABA, 2010. Occurrence and fate of human pharmaceuticals in the environment. Rev Environ Contam Toxicol. 202:53-154.

OECD, 2000. Series on Testing and Assessment No. 23. Guidance document on aquatic toxicity testing of difficult substances and mixtures. Environment Directorate, Organisation For Economic Co-Operation And Development, Paris. ENV/JM/MONO(2000)6.

O'Flynn D, Lawler J, Yusuf A, Parle-McDermott A, Harold D, Mc Cloughlin T, Holland L, Regan F, Blanaid W, 2021. A review of pharmaceutical occurrence and pathways in the aquatic environment in the context of a changing climate and the COVID-19 pandemic. Anal. Methods 13:575.

Ortiz de García SA, Pinto Pinto G, García-Encina PA, IrustaMata R, 2014. Ecotoxicity and environmental risk assessment of pharmaceuticals and personal care products in aquatic environments and wastewater treatment plants. Ecotoxicology 23:1517-1533. 
Parvez S, Venkataraman C, Mukherji S, 2006. A review on advantages of implementing luminescence inhibition test (Vibrio fischeri) for acute toxicity prediction of chemicals. Environ. Int. 32:265-268.

Price P, Han X, Junghans M, Kunz P, Watts C, Leverett D, 2012. An application of a decision tree for assessing effects from exposures to multiple substances to the assessment of human and ecological effects from combined exposures to chemicals observed in surface waters and wastewater effluents. Environ. Sci. Eur. 24:1-13.

R Core Team, 2021. R: A Language and Environment for Statistical Computing. R Foundation for Statistical Computing, Vienna, Austria. Available from: http://www.R-project.org/

Rodea-Palomares I, Petre AL, Boltes K, Leganés F, PerdigónMelón JA, Rosal R, Fernández-Piñas F, 2010. Application of the combination index (CI)-isobologram equation to study the toxicological interactions of lipid regulators in two aquatic bioluminescent organisms. Water Res. 44:427-438.

SCHER, SCCS, SCENIHR, 2012. Toxicity and Assessment of Chemical Mixtures. 2012. European Union Publications. Available from: https:/op.europa.eu/en/publication-detail//publication/ffab4074-6ce5-4f87-89b7-fbd438943b54/language-en

Silva E, Rajapakse N, Kortenkamp A, 2002. Something from "nothing"- Eight weak estrogenic chemicals combined at concentrations below NOECs produce significant mixture effects. Environ. Sci. Technol. 36:1751-1756.

Sprague JB, 1970. Measurement of pollutant toxicity to fish. II. Utilizing and applying bioassay results. Water Res. 4:3-32.

Thrupp TJ, Runnalls TJ, Scholze M, Kugathas S, Kortenkamp A, Sumpter JP, 2018. The consequences of exposure to mixtures of chemicals: Something from 'nothing' and 'a lot from a little' when fish are exposed to steroid hormones. Sci. Total Environ. 619-620:1482-1492.

United Nations, 2013. Globally harmonized system of classifi- cation and labelling of chemicals, 5th ed. ST/SG/AC. 10/30/Rev.5. United Nations Publications, New York.

van Gestel CAM, Jonker MJ, Kammenga JE, Laskowski R, Svendsen C, 2011. Mixture toxicity: linking approaches from ecological and human toxicology. CRC Press, Boca Raton.

Verhaar HJM, Van Leeuwen CJ, Hermens JLM, 1992. Classifying environmental pollutants. 1: Structure-activity relationships for prediction of aquatic toxicity. Chemosphere 25:471-491.

Vighi M, Migliorati S, Monti GS 2009. Toxicity on the luminescent bacterium Vibrio fischeri (Beijerinck). I: QSAR equation for narcotics and polar narcotics. Ecotoxicol. Environ. Saf. 72:154-161.

Villa S, Di Nica V, Bellamoli F, Pescatore T, Ferrario C, Finizio A, Lencioni V, 2018a. Effects of a treated sewage effluent on behavioural traits in Diamesa cinerella and Daphnia magna. J. Limnol. 77:1760.

Villa S, Di Nica V, Castiglioni S, Finizio A, 2020. Environmental risk classification of emerging contaminants in an alpine stream influenced by seasonal tourism. Ecol. Indic. 115:06428.

Villa S, Di Nica V, Pescatore T, Bellamoli F, Miari F, Finizio A, Lencioni V, 2018b. Comparison of the behavioural effects of pharmaceuticals and pesticides on Diamesa zernyi larvae (Chironomidae). Env. Poll. 238:130-139.

Warne MStJ, Hawker DW, 1995. The number of components in a mixture determines whether synergistic and antagonistic or additive toxicity predominate: The funnel hypothesis. Ecotoxicol. Environ. Saf. 31:23-28.

Weltens R, Deprez K, Michiels L, 2014. Validation of Microtox as a first screening tool for waste classification. Waste Manag. 34:2427-2433.

Weltens R, Vanermen G, Tirez K, Robbens J, Deprez K, Michiels L, 2012. Screening tests for hazard classification of complex waste materials - Selection of methods. Waste Manag. 32:2208-2217. 